\title{
壳寡糖对干旱胁迫下油菜光合参数的影响
}

\section{李 艳 ${ }^{1,2,3}$ 赵小明 $2,{ }^{*}$ 夏秀英 ${ }^{4}$ 奕雨时 ${ }^{4}$ 杜昱光 $^{2, *}$ 李凤兰 ${ }^{1}$}

( ${ }^{1}$ 北京林业大学生物科学与技术学院, 北京 $100083 ;{ }^{2}$ 中国科学院大连化学物理研究所, 辽宁大连 $116023 ;{ }^{3}$ 辽宁师范大学生命科 学学院, 辽宁大连 $116029 ;{ }^{4}$ 大连理工大学环境与生命学院, 辽宁大连 116024)

摘 要: 采用酶解法获得壳寡糖, 利用 CIRAS-2 型便携式光合仪测定干旱胁迫下油菜光合参数。其叶片的净光合速 率 $\left(P_{\mathrm{n}}\right)$ 、气孔导度 $\left(G_{\mathrm{s}}\right)$ 、胞间 $\mathrm{CO}_{2}$ 浓度 $\left(C_{\mathrm{i}}\right)$ 显著降低; 气孔限制值 $\left(L_{\mathrm{s}}\right)$ 显著提高。说明气孔限制是油菜在干旱胁迫下 $P_{\mathrm{n}}$ 降低的主要原因。用 $50 \mathrm{mg} \mathrm{L}^{-1}$ 壳寡糖溶液喷施油菜的幼苗叶片后发现干旱胁迫下油菜叶片的净光合速率 $\left(P_{\mathrm{n}}\right)$ 、气 孔导度 $\left(G_{\mathrm{s}}\right)$ 、胞间 $\mathrm{CO}_{2}$ 浓度 $\left(C_{\mathrm{i}}\right)$ 显著提高; 气孔限制值 $\left(L_{\mathrm{s}}\right)$ 显著降低。说明壳葟糖有助于减轻气孔限制引起的净光合 速率的降低。壳皃糖还能促进幼苗根系生长。

关键词: 油菜; 壳寡糖; 净光合速率; 气孔导度; 胞间 $\mathrm{CO}_{2}$ 浓度; 气孔限制值; 干重

\section{Effects of Oligochitosan on Photosynthetic Parameter of Brassica napus Seedlings under Drought Stress}

\author{
LI Yan ${ }^{1,2,3}$, ZHAO Xiao-Ming ${ }^{2, *}$, XIA Xiu-Ying ${ }^{4}$, LUAN Yu-Shi $^{4}$, DU Yu-Guang ${ }^{2, *}$, and LI Feng-Lan ${ }^{1}$ \\ $\left({ }^{1}\right.$ College of Life Science and Technology, Beijing Forestry University, Beijing $100083 ;{ }^{2}$ Dalian Institute of Chemical Physics, Chinese Academy \\ of Sciences, Dalian 116023, Liaoning; ${ }^{3}$ College of Life Science, Liaoning Normal University, Dalian 116029, Liaoning; ${ }^{4}$ Dalian University of \\ Technology, School of Environmental \& Biological Science \& Technology, Dalian 116024, Liaoning, China)
}

\begin{abstract}
Effect of oligochitosan on enzyme activities associated with the resistance to epiphyte and bacteria diseases of plants has been reported. Oligochitosan was prepared in our labarotory. Brassica napus L. seedlings without or with oligochitosan treatment under drought stress were determined with PP-Systems company CIRAS-2 portable Photosynthetic apparatus in the trial. The result indicated that the net photosynthetic rate $\left(P_{\mathrm{n}}\right)$, stomatal conductance $\left(G_{\mathrm{s}}\right)$, intercellular $\mathrm{CO}_{2}$ concentration $\left(C_{\mathrm{i}}\right)$ decreased significantly $(P<0.05)$, while stomatal limitation $\left(L_{\mathrm{s}}\right)$ increased significantly $(P<0.05)$ in Brassica napus L. seedlings under drought stress. The $P_{\mathrm{n}}, G_{\mathrm{s}}$, and $C_{\mathrm{i}}$ increased, while $L_{\mathrm{s}}$ decreased when Brassica napus seedlings treated with $50 \mathrm{mg} \mathrm{L}^{-1}$ oligochitosan under drought stress. It indicated oligochitosan treatments are beneficial to reduce the drop of $P_{\mathrm{n}}$ caused by stomatal limitation in Brassica napus L. seedlings under drought stress. The dry weight of roots of rapes also increased by spraying oligochitosan under drought stress.
\end{abstract}

Keywords: Brassica napus; Oligochitosan; Net photosynthetic rate $\left(P_{\mathrm{n}}\right)$; Stomatal conductance $\left(G_{\mathrm{s}}\right)$; Intercellular $\mathrm{CO}_{2}$ concentration $\left(C_{\mathrm{i}}\right)$; Stomatal limitation $\left(L_{\mathrm{s}}\right)$; Dry weight (DW)

水资源短缺是制约农业发展的一个全球性问 题 ${ }^{1]}$ 。目前全球约 $43 \%$ 的耕地受到干旱、半干旱的威 胁 ${ }^{[2-3]}$ 。干旱胁迫严重水资源短缺是制约农业发展的一 个全球性问题 ${ }^{[1]}$ 。目前全球约影响着作物的生长发育, 在干旱胁迫下, 由于气孔限制降低了叶片光合速率及 胞间 $\mathrm{CO}_{2}$ 浓度, 导致光合作用的减弱 ${ }^{[4]}$, 最终慊收, 甚 至绝收。葟糖是植物抗性诱导剂。1976 年 Ayers 等发
现细胞壁的寡糖碎片能诱导植保素的合成 ${ }^{[5]}$ 。1985 年 Peter Albersheim 及其同事发现霉菌细胞壁片段 $\beta$-葡聚 糖能够激活植物抗性反应, 并且首次提出了葟糖素 (oligosacchrins) 这个新概念 ${ }^{[6]}$ 。几丁质和壳聚糖是动 物甲壳的主要成分, 也是许多真菌细胞壁的组成成 分。几丁质是 $\mathrm{N}$-乙酰氨基葡萄糖通过 $\beta-1,4$ 键连接而 形成的线性多聚糖，其部分脱乙酰化的产物即为壳 
聚糖。几丁质的溶解性很差, 壳聚糖能溶于弱酸中, 因此壳聚糖较几丁质有较多的应用。壳聚糖不仅 能有效诱导植物抗病性, 在田间对作物病害的防治 有明显的效果, 而且对植物病原菌生长有抑制作 用 ${ }^{[7-8]}$ 。壳聚糖被认为是很有应用潜力的激发子。但 是, 由于几丁质和壳聚糖的水溶性差, 限制了它们 在农业生产上的应用。因此, 水溶性好的寡糖引起了 人们的极大关注。作者所在的课题组应用酶法降解壳 聚糖获得的壳寡糖有多方面的生理功能 ${ }^{[9-10]}$ 。特别是对 植物病毒病的防治效果明显 ${ }^{[11]}$ 。人们对其诱抗机理进 行了较深入的研究 ${ }^{[6,8-11]}$ 。实验发现壳寡糖信号分子被 植物细胞识别后, 可以诱导产生过敏反应和系统获得 性抗性等多种防御反应 ${ }^{[12]}$, 诱导植物抗病性相关基因 表达 ${ }^{[13-16]}$, 诱导烟草叶表皮细胞产生 $\mathrm{NO}$ (一氧化氮) 和 $\mathrm{H}_{2} \mathrm{O}_{2}$ (过氧化氢) $)^{[17]}$, 进而参与诱导虫豆气孔关闭的信 号转导 ${ }^{[18]}$, 对植物抗旱非常有利。但未见报道干旱胁 迫下壳寡糖对作物光合参数的影响。

\section{1 材料与方法}

\section{1 材料}

油菜(Brassica nupus L.)品种沪油15, 来自中国 科学院上海植物生理研究所。

\section{2 研究内容和方法}

\subsection{1 材料处理及测定项目将 160 棵油菜幼苗} 分别栽种于同样大小的装有等量、同土质的盆内, 长至4 8叶期后分成4组, 浇以充足的水, 一组叶面 喷 $\mathrm{dH}_{2} \mathrm{O}$ 后未进行干旱处理 (对照 1 ), 其他 3 组叶面分 别喷 $\mathrm{dH}_{2} \mathrm{O}$ (对照 2 ) 及 $50 \mathrm{mg} \mathrm{L}^{-1}$ 壳葟糖1次及3次 (每 天1次, 连续喷 $3 \mathrm{~d}$ ) 后进行干旱处理。处理条件为土 壤含水量 $3.31 \% \sim 6.02 \%$; 温度 : $10 \sim 22^{\circ} \mathrm{C}$; 空气相对

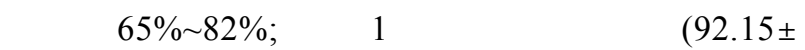
$0.74) \%$; 其余3组叶片相对含水量 : $(77.75 \pm 0.61) \%$ 。 处理后, 第 3 天、第 6 天和第 9 天进行光合参数测定。 第9天还测定幼苗 $(\mathrm{S})$ 、地上部分 $(\mathrm{AP})$ 和根 $(\mathrm{R})$ 的干, 重复2次。采用Excel和SPSS13软件进行数据分析。

\subsection{2 光合参数的测定采用英国PP-Systems公} 司CIRAS-2型便携式光合作用测定仪对油菜完全展 开的第二叶进行净光合速率 $\left(P_{\mathrm{n}}\right)$ 、大气 $\mathrm{CO}_{2}$ 浓度 $\left(C_{\mathrm{a}}\right)$ 、 气孔导度 $\left(G_{\mathrm{s}}\right)$ 、细胞间隙 $\mathrm{CO}_{2}$ 浓度 $\left(C_{\mathrm{i}}\right)$ 等光合参数的 测定。气孔限制值 $\left(L_{\mathrm{s}}\right)$ 由 $\left(1-C_{\mathrm{i}} / C_{\mathrm{a}}\right)$ 计算所得。测定 过程中光强约为 $1500 \mu \mathrm{mol} \mathrm{m} \mathrm{m}^{-2} \mathrm{~s}^{-1}$, 大气温度 $(22 \pm$ $2)^{\circ} \mathrm{C}$ 大气 $\mathrm{CO}_{2}$ 浓度变化范围为 $(487 \pm 10) \mu \mathrm{mol} \mathrm{L}^{-1}$ 。 测定时间为 $10: 00-11: 30$ 。第9天测定幼苗 $(\mathrm{S})$ 、地上
部分(AP)和根(R)。

\section{2 结果与分析}

2.1 干旱胁迫下壳寡糖对油菜净光合速率的影响

图 1 可以看出，随着干旱胁迫时间的延长, 对照 2 与对照 1 相比 $P_{\mathrm{n}}$ 呈现显著下降趋势。喷施 $50 \mathrm{mg} \mathrm{L}^{-1}$ 壳寡糖 1 次后第 3 天、第 6 天和第 9 天能明显提高干 旱胁迫下油菜的净光合速率, 增长率分别为 $45 \% 、 91 \%$ 和 $37 \%$ 。喷施壳臭糖 3 次后第 3 天、第 6 天和第 9 天 也能提高干旱胁迫下油菜的净光合速率，增长率分别 为 $33 \% 、 29 \%$ 和 $67 \%$ 。说明壳寡糖可以减轻干旱胁迫 下油菜叶片光合速率的下降程度, 有利于维持干旱胁 迫下油菜叶片较高水平的光合作用。

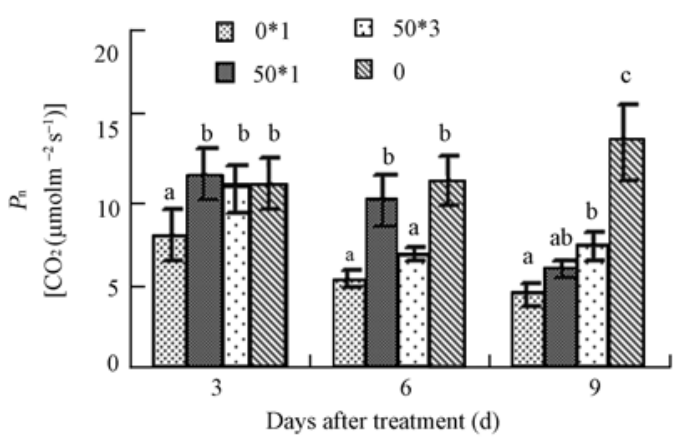

图 1 干旱胁迫下壳寡糖对油菜净光合速率的影响

Fig. 1 The influence of oligochitosan on photosynthesis of rape under drought stress

0 : 对照 $1 ; 0 * 1$ : 对照 $2 ; 50 * 1 ， 50 * 3$ 分别为用 $50 \mathrm{mg} \mathrm{L}^{-1}$ 的壳

寡糖处理 1 次及 3 次(下同), 不同字母代表差异显著。

0 : control 1; $0 * 1$ : control 2; 50*1: Treatment with oligochitosan 1 time, 50*3: Treatment with oligochitosan 3 times.

Bars with different letter designations are significantly different at $P<0.05$.

\section{2 干旱胁迫下壳寡糖对油菜气孔导度的影响}

由图 2 可以看出, 随着干旱胁迫时间的延长对 照 2 与对照 1 相比 $G_{\mathrm{s}}$ 显著下降。喷施壳寡糖 1 次后 第 3 天和第 6 天能显著提高干旱胁迫下油菜的气孔 导度，增长率分别为 $71 \%$ 和 $78 \%$ ，第 9 天差异不显

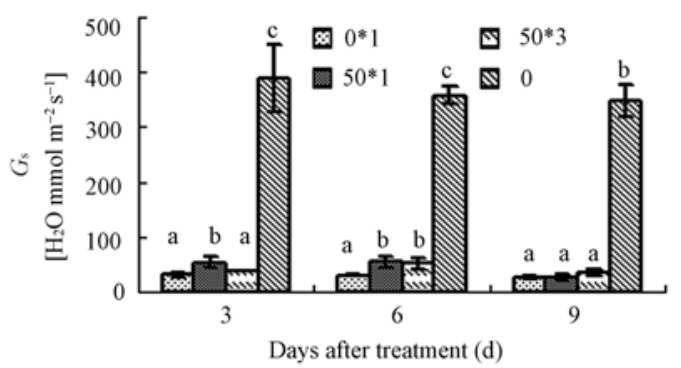

图 2 干旱胁迫下壳寡糖对油菜气孔导度的影响 Fig. 2 The influence of oligochitosan on $G_{\mathrm{S}}$ of rape under 


\section{drought stress}

著。喷施壳寡糖 3 次后, 第 6 天能明显提高干旱胁 迫下油菜的气孔导度, 增长率分别为 $22 \% 、 69 \%$ 和 $33 \%$ 。说明壳寡糖减轻了干旱胁迫下油菜气孔导度 的下降程度, 有利于维持干旱胁迫下油菜叶片较高 水平的气孔导度。

2.3 干旱胁迫下壳寡糖对油菜胞间 $\mathrm{CO}_{2}$ 浓度和 气孔限制值的影响

由图 3 和图 4 可以看出, 随着干旱胁迫时间的 延长, 对照 2 与对照 1 相比 $C_{\mathrm{i}}$ 显著下降, $L_{\mathrm{s}}$ 显著提 高。喷施壳寡糖 1 次后第 3 天、第 6 天和第 9 天与 对照 2 相比 $C_{\mathrm{i}}$ 提高，为对照 2 的 $140 \% 、 139 \%$ 和 $128 \%$; $L_{\mathrm{s}}$ 下降，为对照 2 的 $83 \%$ 、85\%和 $90 \%$ 。喷施壳寡糖 3 次后第 3 天、第 6 天和第 9 天与对照 2 相比 $C_{\mathrm{i}}$ 提 高, 为对照 2 的 $134 \% 、 132 \%$ 和 $130 \% ; L_{\mathrm{s}}$ 下降，为对 照 2 的 $85 \%$ 、87\%和 $89 \%$ 。

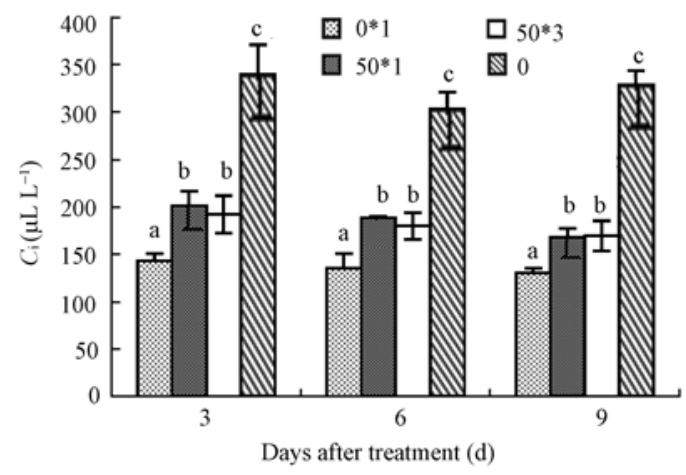

图 3 干旱胁迫下壳寡糖对油菜胞间 $\mathrm{CO}_{2}$ 浓度的影响

Fig. 3 The influence of oligochitosan on $C_{\mathrm{i}}$ of rape under drought stress

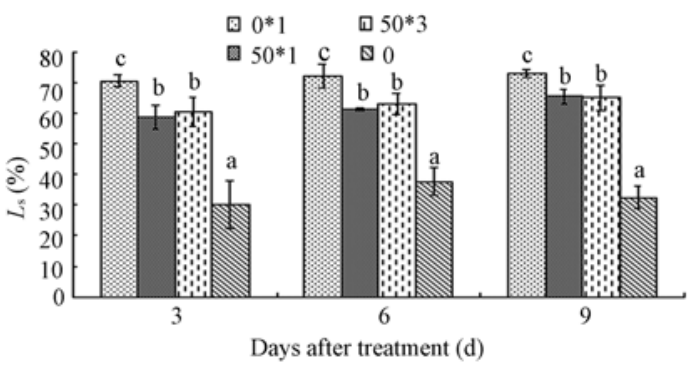

图 4 干旱胁迫下壳寡糖对油菜气孔限制值的影响

Fig. 4 The influence of oligochitosan on $L_{\mathrm{s}}$ of rape under drought stress

\section{4 干旱胁迫下壳寡糖对油菜干重的影响}

由图 5 可以看出, 对照 2 与对照 1 相比幼苗、地 上部分和根的干重显著下降。喷施壳寡糖 1 次和 3 次 后第 9 天与对照 2 相比, 幼苗和地上部分的干重差异
不显著而根干重显著提高，为对照 2 的 $174 \%$ 和 $159 \%$ 。

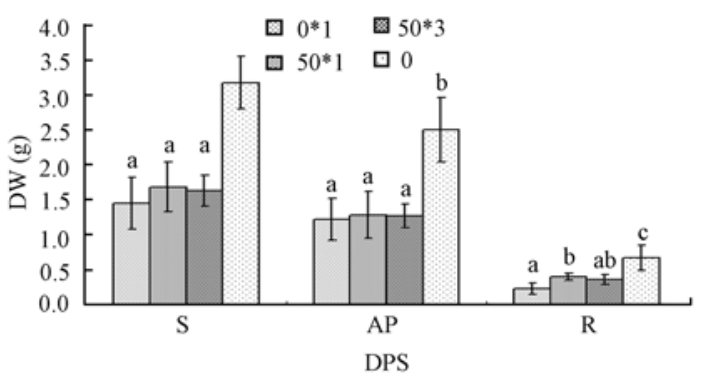

图 5 干旱胁迫下壳寡糖对油菜干重的影响

Fig. 5 The influence of oligochitosan on dry weight of rape under drought stress

\section{3 讨论}

作物 $P_{\mathrm{n}}$ 下降的原因可分为气孔限制(主要是受 气孔导度的影响)和非气孔限制(受内部调控机制的 影响, 如光合作用相关的酶活性, 光系统 II 反应中 心电子流的状态等), 气孔限制是干旱胁迫下净光合 速率下降的主要原因 ${ }^{[4]}$ 。油菜在干旱胁迫下, $P_{\mathrm{n}} 、 G_{\mathrm{s}}$ 和 $C_{\mathrm{i}}$ 下降, $L_{\mathrm{s}}$ 升高, 推测其 $P_{\mathrm{n}}$ 降低的主要原因是气 孔限制。叶片喷施 $50 \mathrm{mg} \mathrm{L}^{-1}$ 壳寡糖 1 次和 3 次后, 与 对照 2 相比干旱胁迫下油菜的 $P_{\mathrm{n}} 、 G_{\mathrm{s}}$ 和 $C_{\mathrm{i}}$ 提高, $L_{\mathrm{s}}$ 下降。说明 $50 \mathrm{mg} \mathrm{L}^{-1}$ 壳寡糖有助于减轻气孔限制引 起的净光合速率的降低。喷施 $50 \mathrm{mg} \mathrm{L}^{-1}$ 壳寡糖 1 次 后第 6 天净光合速率增长 91\%，其增长幅度明显高 于气孔导度及胞间 $\mathrm{CO}_{2}$ 浓度的升高幅度。推测外施 壳寡糖不仅缓解了气孔限制引起的 $P_{\mathrm{n}}$ 的降低, 而且 改善了油菜的生理调节机制。对于油菜 $P_{\mathrm{n}}$ 及干重叶 片喷施 $50 \mathrm{mg} \mathrm{L}^{-1}$ 壳寡糖 1 次高于喷 3 次, 可能过度 喷施和高浓度喷施一样不利于生长和诱导抗性。

据报道壳寡糖能够促进油菜生长, 增加产量 ${ }^{[19]}$ 。 $P_{\mathrm{n}}$ 提高导致作物同化力加强, 进而体内干物质增 加。实验证明油菜净光合作用与根干重正相关, 说 明 $P_{\mathrm{n}}$ 提高首先促进根生长。作物生长发育过程中需 要的水分及营养主要是通过根系吸收的, 发育良好 的根系为作物生长及提高产量提供了物质基础。

作者研究发现油菜(干旱胁迫及非胁迫下)叶片 喷施 25 75 mg L $\mathrm{mg}^{-1}$ 壳寡糖后 $30 \mathrm{~min}$, 叶片气孔开度 明显下降(另文发表)。寡聚半乳糖醛酸, 壳聚糖能够 诱导西红柿和鸭跖草气孔开度减少，而且叶片气孔 开度下降与植物抗病密切相关 ${ }^{[20]}$ 。前人的研究证明 在活性氧爆发过程中 $\mathrm{H}_{2} \mathrm{O}_{2}$ 产生是防止病菌入侵的

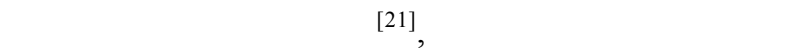
片表皮细胞产生 $\mathrm{NO}$ 和 $\mathrm{H}_{2} \mathrm{O}_{2}$, 在免疫系统中起着重 要的作用 ${ }^{[17]}$ 。壳葟糖既能诱导植物抗病性相关基因 
表达 ${ }^{[6-9]}$, 提高植物抗病性 ${ }^{[12]}$, 又有利于缓解干旱胁 迫下油菜光合作用的下降，提高其抗旱性。这对壳 寡糖在农业生产中的应用非常有利。

\section{4 结论}

壳寡糖不仅有助于减轻气孔限制引起的油菜净 光合速率的降低, 还能促进幼苗根系生长。

致谢: 在光合参数测定过程中得到大连理工大学安利 佳老师和魏立君同学的热心帮助，在此表示感谢!

\section{References}

[1] Glombitza S, Dubuis P H, Thulke O, Welzl G, Bovet L, Gotz M, Affenzeller M, Geist B, Hehn A, Asnaghi C, Ernst D, Seidlitz H K, Gundlach H, Mayer K F, Martinoia E, Werck R D, Mauch F, Schaffner A. Crosstalk and differential response to abiotic and biotic stressors reflected at the transcriptional level of effector genes from secondary metabolism. Plant Mol Biol, 2004, 51: 1-19

[2] Wang J-G(王建革), Su X-H(苏晓华), Zhang B-Y(张冰玉), Huang Q-J(黄秦军), Zhang X-H(张香华), Sun B-Q(孙宝启). Several questions needed attention for drought resistance in plant. Chin Agric Sci Bull (中国农学通报), 2004, 20(4): 93-96 (in Chinese with English abstract)

[3] Ashraf M, Foolad M R. Roles of glycine betaine and proline in improving plant abiotic stress resistance. Environ Exp Bot, 2007, 59: 206-216

[4] Reddy A R, Chaitanya K V, Vivekanandan M. Drought- induced responses of photosynthesis and antioxidant metabolism in higher plant. J Plant Physiol, 2004, 161: 1189-1202

[5] Ayer A R, Ebel J, Finelli F, Berger N, Albersheim P. Host-pathogen interactions: IX. Quantitative assays of elicitor activity and characterization of the elicitor present in the extracellular medium of cultures of Phytophthora megasperma var. sojae. Plant Physiol, 1976, 57: 751-759

[6] Albersheim P, Darvill A G. Oligosaccharins: Novel molecules that can regulate growth, development, reproduction, and defense against disease in plant. Sci Am, 1985, 253: 58-64

[7] Ben-Shalom N, Ardi R, Pinto R, Aki C, Fallik E. Controlling gray mould caused by Botrytis cinerea in cucumber plants by means of chitosan. Crop Prot, 2003, 22: 285-290

[8] Bautista-Baños S, Hernández-Lauzardo A N, Velázquez-del Valle M G, Hernández-Lópeza M, Ait Barka E, BosquezMolinac E, Wilson C L. Chitosan as a potential natural compound to control pre and postharvest diseases of horticultural commodities. Crop Prot, 2006, 25: 108-118

[9] Zhang H, Du Y G, Yu X J. Preparation of chitooligosaccharides from chitosan by an enzyme mixture. Carbohydrate Res, 1999 ,
320: $257-260$

[10] Guo H-L(郭红莲), Bai X-F(白雪芳), Du Y-G(杜昱光), Li $\mathrm{S}-\mathrm{G}$ (李曙光). The effect of oligochitosan on active oxygen metabolism of suspension strawberry cells. Acta Hort Sin (园 艺学报), 2003, 30(5): 577-579 (in Chinese with English abstract)

[11] Zhao X-M(赵小明), Du Y-G(杜昱光), Bai X-F(白雪芳). The field experiment of oligochitosan controlling plant virus disease. Chin Agric Sci Bull (中国农学通报), 2004, 20(4): 245-247 (in Chinese with English abstract)

[12] Shi Y(石瑛), Du Y-G(杜昱光), Bai X-F(白雪芳). Signal transduction induced by oligosaccharides in plant. Life Sci Res (生命科学研究), 2001，5(1): 29-32 (in Chinese with English abstract)

[13] Feng B(冯斌), Wang C-H(王春晗), Chen Y-F(陈娅斐), Bai $\mathrm{X}-\mathrm{F}$ (白雪芳), Du Y-G(杜昱光). mRNA different display analysis of plant resistance related gene induced by oligochitosan. Biotechnology (生物技术), 2004, 14(6): 13-16 (in Chinese with English abstract)

[14] Zhang F-Y(张付云), Feng B(冯斌), Du Y-G(杜昱光), Bai $\mathrm{X}-\mathrm{F}$ (白雪芳), Zhang Y-K(张玉奎). Expression of tobacco SKP1 gene induced by oligochitosan. J Plant Physiol Mol Biol (植物生理与分子生物学学报), 2005, 31(2): 213-216 (in Chinese with English abstract)

[15] Chen Y-F(陈娅斐), Feng B(冯斌), Zhao X-M(赵小明), Bai $X-F$ (白雪芳), Du Y-G(杜昱光). Pal activity and TMV inhibition ability in transformed antisense mapk tobacco induced by oligochitosan. Chin J Appl Environ Biol (应用与环境生物学 报), 2003, 11(6): 665-668 (in Chinese with English abstract)

[16] Yin H, Li S, Zhao X, Du Y, Ma X. cDNA microarray analysis of gene expression in Brassica napus treater with oligochitosan elicitor. Plant Physiol Biochem, 2006, 44: 910-916

[17] Zhao X M, She X P, Du Y G, Liang X M. Induction of antiviral resistance and stimulary effect by oligochitosan in tobacco. Pesticide Biochem Physiol, 2007, 87: 78-84

[18] She X P, Song X G, He J M. Role and relationship of nitric oxide and hydrogen peroxide in light/dark-regulated stomatal movement in Vicia faba. Acta Bot Sin, 2004, 46: 1292-1300

[19] Lu Z-G(陆正罡), Qian X-G(钱小刚), Peng Y(彭义), Ma G-R(马国瑞). An applied study of chitoligmer rape seed coating agent. Seed (种子), 2003, (4): 38-40 (in Chinese with English abstract)

[20] Lee S, Choi H, Suh S, Doo I S, Oh K Y, Choi E J, Ann T, Taylor S, Low P S, Lee Y. Oligogalacturonic acid and chitosan reduce stomatal aperture by inducing the evolution of reactive oxygen species from guard cells of tomato and commelina communis. Plant Physiol, 1999, 121: 147-152

[21] Wim V C, Marc V M. $\mathrm{H}_{2} \mathrm{O}_{2}$ and NO: Redox signals in disease resistance. Res Newslett, 1998, 3: 330-334 